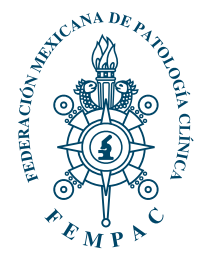

Carta al Editor

\title{
COVID-19: el enigma de los caminantes asintomáticos
}

\section{COVID-19: the enigma of asymptomatic walkers}

\author{
Rojas-Zumarán Víctor,*,‡ Walttuoni-Picón Eder, ${ }^{\ddagger}$ Lozada-Diaz Rocío, \\ Tapia-Quispe José Luis, ${ }^{*, \|}$ Cruz-Gonzales Gloria ${ }^{\ddagger}$
}

\section{* Hospital Nacional Docente Madre-Niño San Bartolomé. \\ Lima, Perú. \\ ${ }^{\ddagger}$ Facultad de Tecnología Médica, Universidad Nacional Federico Villareal. Lima, Perú. \\ $\S$ Escuela Profesional de Tecnología Médica, Universidad Nacional de Jaén. Cajamarca, Perú. \\ "| Escuela Profesional de Tecnología Médica, Universidad Privada Norbert} Wiener. Lima, Perú.

Correspondencia: Walttuoni-Picón Eder Jr. Gral Issac Recavarren 768 Urb. Moran de la Cadena.

Teléfono: 924316760. E-mail:

edermarks995@ hotmail.com / 2015025422@unfv. edu.pe.

Recibido: 29/04/2020 Aceptado: 02/05/2020

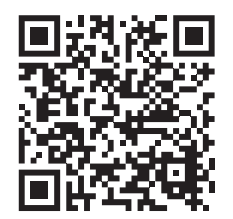

Dr. Alberto Zamora Palma, Editor de la Revista Mexicana de Patología Clínica

D urante siglos el mundo ha estado expuesto a varias pandemias de naturaleza viral o bacteriana que han amenazado a la raza humana. Según la Organización Mundial de la Salud (OMS), el 31 de diciembre de 2019 la Comisión Municipal de Salud de Wuhan, China notifica un conglomerado de casos de neumonía en Wuhan (provincia de Hubei). Posteriormente se determina que son causados por un nuevo virus (SARS-CoV-2) provocando la denominada «enfermedad por coronavirus 2019» (COVID-19, por sus siglas en inglés). ${ }^{1}$ Esta enfermedad ya había sido reportada en 2003 por la OMS como SARS (síndrome respiratorio agudo severo), de la cual se reportaron 4,836 casos con una mortalidad de $6 \%$ y cuyo origen fue en la provincia de Guangdong, China. ${ }^{2}$

Siendo de transmisión zoonótica presenta un cuadro clínico principalmente de compromiso respiratorio; sin embargo, también se han reportado casos de anosmia (pérdida del olfato, que conlleva frecuentemente a la pérdida del gusto), ${ }^{3}$ los síntomas más habituales son: fiebre $(80 \%)$, tos seca $(76 \%)$, rinorrea, mialgias y/o sensación de fatiga o cansancio (44\%), cefalea (8\%). En pacientes con complicaciones más severas se presenta disnea (55\%), taquipnea, hipoxia y neumonía (10-15\%). ${ }^{4,5}$ Actualmente se está haciendo referencia a nueva sintomatología de compromiso cardiovascular. ${ }^{6}$

La vía de transmisión entre humanos es el contacto directo con secreciones de personas infectadas, principalmente con microgotas o gotas de Flügge que al ser expulsadas pueden alcanzar hasta 2 metros de distancia, las cuales pueden contaminar todo su entorno así como a las personas a su alrededor y todo tipo de superficies. ${ }^{7}$ Desde el momento en que adquiere el virus, la persona se encuentra en periodo de incubación que aproximadamente oscila entre dos y 10 días, $^{8}$ durante el cual no aparece ningún síntoma, seguido de la sintomatología ya descrita que tiene una duración aproximada de dos semanas en casos leves y de tres a seis semanas en casos graves o complejos. . $^{5,6}$

Sin embargo, existe una población que en todo el periodo de infección no presenta síntomas o éstos son imperceptibles, los llamados asintomáticos. Según datos estadísticos el paciente asintomático representa hasta 80$85 \%,{ }^{5}$ llegando a ser una fuente importante en la propagación del virus.

Un suceso que tomó gran relevancia tuvo lugar en el crucero Diamond Princess en Japón, donde se detectaron 634 casos positivos, de los cuales cerca de $50 \%$ eran asintomáticos. Identificar y vigilar los casos asintomáticos es de vital importancia, aunque este tipo de pacientes no puede llegar a presentar síntoma alguno durante la detección de COVID-19, el periodo del paciente de ser transmisible perdura durante tres semanas. He aquí la importancia de considerar a las personas asintomáticas como fuente de transmisibilidad de COVID-19 y de vigilar a este tipo de pacientes para evitar rebrotes y posibles colapsos de los servicios de salud. ${ }^{9}$ 
En un modelo de metapoblación dinámica en red e inferencia bayesiana para inferir características epidemiológicas críticas asociadas con el SARS-CoV-2 se encontró que $86 \%$ de todas las infecciones no estaban documentadas, siendo éstas fuente de infección de 79\% de los casos documentados. ${ }^{10}$

Por lo antecedido, sostenemos que debe identificarse a los asintomáticos, ya que de ellos depende la transmisión permanente a los individuos susceptibles al SARSCOV-2, y lo que es peor, consideramos que son ellos la base de futuros rebrotes. Por tanto, es importante que la población sea sometida a un control social permanente masivo para el diagnóstico de SARS-COV-2 mediante pruebas rápidas de inmunocromatografía y/o RT-PCR (Real Time Polymerase Chain Reaction, por sus siglas en inglés), y dependiendo de la situación socioeconómica de cada país, se deberá georreferenciar a estos pacientes.

Por lo anterior, nos preguntamos si las personas asintomáticas que van caminando e infectando a otras sin siquiera saber que contrajeron el virus se han convertido en reservorios, y si son éstos la causa de olas de infecciones o de los estadios permanentes del virus que implican sus diferentes mutaciones.

\section{REFERENCIAS}

1. Organización Mundial de la Salud. COVID-19: cronología de la actuación de la OMS. [Internet]. 2020. Disponible en: https://www. who.int/es/news-room/detail/08-04-2020-who-timeline---covid-19
2. Barriga Angulo G, Arumir Escorza C. Información sobre el síndrome respiratorio agudo severo (SRAS). Rev Mex Patol Clin. 2003; 50 (1): 6-11.

3. Lechien JR, Chiesa-Estomba CM, De Siati DR, Horoi M, Le Bon $\mathrm{SD}$, Rodriguez A et al. Olfactory and gustatory dysfunctions as a clinical presentation of mild-to-moderate forms of the coronavirus disease (COVID-19): a multicenter European study. Eur Arch Otorhinolaryngol. 2020. doi: 10.1007/s00405-020-05965-1. [Epub ahead of print]

4. Otoya-Tono AM, García M, Jaramillo-Moncayo C, Wills C, Campos AM. COVID-19: generalidades, comportamiento epidemiológico y medidas adoptadas en medio de la pandemia en Colombia. Acta Otorrinolaringol Cir Cabeza Cuello. 2020; e-Boletín (Abril): 4-13.

5. Salas-Asencios R, lannacone-Oliver R, Guillén-Oneeglio A, Tantaléan-Da Fieno J, Alvariño-Flores L, Castañeda-Pérez L et al. Coronavirus COVID-19: knowing the cause of the pandemic. The Biologist (Lima). 2020; 18 (1): 9-27.

6. Madjid M, Safavi-Naeini P, Solomon SD, Vardeny O. Potential effects of coronaviruses on the cardiovascular system: a review. JAMA Cardiol. 2020. doi: 10.1001/jamacardio.2020.1286. [Epub ahead of print]

7. Centro de Coordinación de Alertas y Emergencias Sanitarias de España. Información científica-técnica. Enfermedad por coronavirus, COVID-19 [Internet]. 2020.

8. Ministerio de Salud del Perú. Documento Técnico: "Plan Nacional de Preparación y Respuesta frente al riesgo de introducción del Coronavirus 2019-nCoV". 2020.

9. Mizumoto K, Kagaya K, Zarebski A, Chowell G. Estimating the asymptomatic proportion of coronavirus disease 2019 (COVID-19) cases on board the Diamond Princess cruise ship, Yokohama, Japan, 2020. Euro Surveill. 2020; 25 (10). doi: 10.2807/1560-7917. ES.2020.25.10.2000180.

10. Li R, Pei S, Chen B, Song Y, Zhang T, Yang W et al. Substantial undocumented infection facilitates the rapid dissemination of novel coronavirus (SARS-CoV-2). Science. 2020; 368 (6490): 489-493. 